\title{
The Hepatoprotective Effect of Diltiazem and Silymarin
}

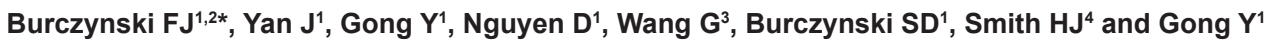 \\ ${ }^{1}$ Faculty of Pharmacy, University of Manitoba, 750 McDermot Avenue, Winnipeg, Manitoba, Canada \\ ${ }^{2}$ Department of Pharmacology and Therapeutics, Faculty of Medicine, University of Manitoba, Winnipeg, Manitoba, Canada \\ ${ }^{3}$ Carolinas Medical Center, Charlotte, NC, USA \\ ${ }^{4}$ Howard J Smith \& Associates Pty Ltd, Melbourne, Australia
}

\begin{abstract}
The clinical use of diltiazem has been suggested to be a reasonable approach for combating free radical induced liver damage. The hepatoprotective effect was observed with $d$-cis diltiazem but not with l-cis diltiazem, suggesting that diltiazem is stereospecific in protecting against lipid peroxidation using isolated microsomes. In the present work we examined $d$-cis diltiazem's antioxidant property using Chang and PLC hepatocyte cultures, and the combination of diltiazem and silymarin since silymarin itself has been reported to possess hepatoprotectant properties. Diltiazem (5 and $10 \mu \mathrm{M}$ ) significantly reduced free radical levels, as did silymarin. The combination of diltiazem and silymarin further protected cells against oxidative stress $(p<0.001)$ compared to either drug alone. Diltiazem, silymarin and the combination were associated with enhanced ATP and reduced Bax and Bax mRNA levels in both cell types with the combination drug treatment showing a much greater difference. The combination of dilitiazem and silymarin further enhanced cell viability. We conclude that low dose diltiazem and silymarin can function as a hepatoprotectant against free radical damage due to oxidative stress. The protective nature extends to reducing levels of the pro-apoptotic Bax protein.
\end{abstract}

Keywords: Dilitiazem; Lipid peroxidation; Microsomes

\section{Introduction}

Calcium channel blockers represent a diverse group of clinically approved pharmacological agents [1]. d-cis Diltiazem is a typical calcium channel blocker that is used in clinical practice for its antihypertensive and antiarrythmic properties. The vascular properties are due to the drugs' ability to decrease vascular contractility and arterial tone by modulating the transmembrane influx of calcium through L-type calcium channels [2]. Diltiazem is also known to possess hepatoprotective properties. The drug protects the liver from ischemia [3], carbon tetrachloride hepatotoxicity [4], acetaminophen hepatotoxicity [5], microsomal lipid peroxidation [6], and hepatocellular oxidative stress [7]. The hepatoprotective role of diltiazem was initially attributed to its vascular properties by enhancing blood flow and thus maintaining the delivery of substrates to cells for normal cell function. Recent work investigating the hepatoprotective property of $d$-cis diltiazem using isolated microsomes ensured that the vasoactive property of the drug would be eliminated such that it would not confound data interpretation. The hepatoprotective action of diltiazem was then studied by investigating whether the drug had any antioxidant property. The study authors reported that diltiazem indeed possessed a significant antioxidant effect [8].

Silymarin, a purified extract from Milk Thistle (Silybum marianun), is a polyphenolic flavonoid that is comprised of four flavonolignans with silibinin being the main active ingredient. Silymarin has been suggested to possess many biological properties including stimulatory effects on key cells of the immune system [9], hepatoprotection [10,11], modulating the oxidant-antioxidant imbalance during drug induced oxidative stress [12]. Many of the functional attributes on liver disease are thought to be due to its antioxidant property $[13,14]$. In this study we investigated whether the addition of silymarin to diltiazem had any additive or synergistic effects on the hepatoprotective properties of diltiazem alone.

\section{Materials and Methods}

All chemicals including $d$-cis diltiazem, silymarin, Torlox, Vitamin $\mathrm{E}$, and dichlorofluorescein diacetate $\left(\mathrm{DCFH}_{2}-\mathrm{DA}\right)$ were purchased from Sigma Chemical (St. Louis, MO). Dulbecco's modified Eagle's medium (DMEM), fetal bovine serum, penicillin, streptomycin, were purchased from GIBCO/BRL. MTT (cell proliferation) and ATPase kits were purchased from Sigma (St. Louis, MO). Cells were obtained from American Type Culture Collection (Manassas, VA, USA).

\section{Cell culture and drug treatment}

Chang and PLC/PRF/5 hepatoma cells were maintained in $25 \mathrm{~cm}^{2}$ culture flasks supplemented with DMEM containing 10\% FBS (DF$10)$, penicillin $(50 \mathrm{U} / \mathrm{mL})$ and streptomycin $(100 \mu \mathrm{g} / \mathrm{ml})$ at $37^{\circ} \mathrm{C}$ in a humidified atmosphere of $95 \%$ air and $5 \% \mathrm{CO}_{2}$ for at least 24 hours. Cells were plated onto culture plates $\left(100 \mathrm{~mm}^{2}\right)$ and exposed to DF-10 media. Following plate confluence cells were treated with drugs for 24 hours for the Western blot and RT-PCR studies. For DCF and MTT assays cells were subcultured onto 96-well black plates (Corning, NY, USA). Following plate confluence, cells were exposed to DF-10 media containing drugs for 24 hours. Control cells were incubated without any drug.

\section{Oxidative stress induced by $\mathrm{H}_{2} \mathrm{O}_{2}$}

Chang and PLC cells were cultured in black plastic 96-well culture plates (Costar\# 3603, Corning Incorporated) at a cell density of 25,000 cells per well with DF-10 culture medium. After overnight incubation in DMEM-10\% FBS, cultures were washed twice with PBS and then incubated with $10 \mu \mathrm{M}$ 2,7-dichlorofluorescin diacetate (DCFH $\left.{ }_{2}-\mathrm{DA}\right)$ in $95 \%$ air $/ 5 \% \mathrm{CO}_{2}$ for 30 minutes at $37^{\circ} \mathrm{C}$ in the dark. Extracellular $\mathrm{H}_{2}$ DCFDA was removed by washing cultures twice with warm PBS. Cellular oxidative stress was induced by incubating cells with $400 \mu \mathrm{M}$

*Corresponding author: Burczynski FJ, Faculty of Pharmacy, University of Manitoba, 750 McDermot Avenue, Winnipeg, Manitoba, R3E 0T5, Canada, Tel: (204)474-6902; Fax: (204)474-7617; E-mail: burczyn@cc.umanitoba.ca

Received July 15, 2013; Accepted July 27, 2013; Published August 03, 2013

Citation: Burczynski FJ, Yan J, Gong Y, Nguyen D, Wang G, et al. (2013) The Hepatoprotective Effect of Diltiazem and Silymarin. Nat Prod Chem Res 1: 111. doi:10.4172/ 2329-6836.1000111

Copyright: (c) 2013 Burczynski FJ, et al. This is an open-access article distributed under the terms of the Creative Commons Attribution License, which permits unrestricted use, distribution, and reproduction in any medium, provided the original author and source are credited. 
$\mathrm{H}_{2} \mathrm{O}_{2}$ in $\mathrm{PBS}$ containing $\mathrm{Ca}^{++}$and $\mathrm{Mg}^{++}$for 20 minutes at $37^{\circ} \mathrm{C}$ in the dark. Negative controls were performed using the same conditions but without $\mathrm{H}_{2} \mathrm{O}_{2}$. Cellular fluorescence intensity of emitted DCF signal was immediately measured using a BMG Fluostar Galaxy fluorescence plate reader (485 $\mathrm{nm}$ excitation wavelength/520 $\mathrm{nm}$ emission wavelength; Durham, NC, USA) equipped with excitation and emission probes directed to the bottom of the plate. Mean fluorescence intensity was calculated from triplicate cultures of control and drug treated cells. Results were expressed in arbitrary fluorescence units (AFU).

\section{Cell viability/Cell proliferation assay}

The MTT assay was used to assess cell growth and viability. Living cells reduce MTT (3-(4,5-Dimethylthiazol-2-yl)-2,5diphenyltetrazolium bromide, a tetrazole) to purple formazan by functional mitochondria. Assay conditions were conducted as outlined by the manufacturer (Sigma, St. Louis, MO). Briefly, Chang and PLC cells were cultured in 96-well plates at a concentration of $3 \times 10^{4}$ cells/ well. Following exposure to diltiazem and/or silymarin for 24 hours, $10 \mu \mathrm{l}$ of the MTT solution (10\% of the culture volume) was added to each well. Cells were incubated with the MTT solution for an additional 3.5 hours at which time the culture media was removed and the MTT solvent added to the wells $(100 \mu \mathrm{l})$. Absorbance of the colour solution was recorded at $570 \mathrm{~nm}$ using a spectra Max 190 (Molecular Devices) plate reader.

\section{Cellular ATP levels}

A bioluminescent assay was employed for the determination of total cellular ATP levels. Procedural details were followed as outlined by the manufacturer (Sigma, St. Louis, MO).

\section{Bax western blot}

Cells were plated onto culture plates $\left(100 \mathrm{~mm}^{2}\right)$ and exposed to DF10 media and drug treatment for 24 hours. Cells were then treated with $400 \mu \mathrm{M} \mathrm{H}_{2} \mathrm{O}_{2}$ for $20 \mathrm{~min}$. Total cellular protein was determined using a protein assay kit (Life Science Research Division). Cellular proteins $(20 \mu \mathrm{g})$ were subjected to SDS-PAGE with 15\% SDS-polyacrylamide gel. Titration of primary antibody was 1:1000 for rabbit anti-Bax and 1:3000 for mouse anti- $\beta$-Actin. The secondary antibody was antirabbit antibody for Bax and anti-mouse antibody for $\beta$-Actin (1:1000 dilutions). Protein-antibody complexes were detected by enhanced chemiluminescence (ECL system, Amersham). The optical density (OD) values of each target protein band were determined by using $\mathrm{NIH}$ Imaging software. Protein loading variation was corrected by normalization of $\beta$-Actin.

\section{Bax RT-PCR}

Cells were plated onto culture plates $\left(100 \mathrm{~mm}^{2}\right)$ and exposed to DF-10 media and drug treatment for 24 hours followed by $20 \mathrm{~min}$ of $400 \mu \mathrm{M} \mathrm{H}_{2} \mathrm{O}_{2}$ incubation. Total RNA was isolated from treated cells using TRIzol LS reagent as described in the manufacturer's manual. PCR was performed by using the Advantage PCR kit, polymerase mix, and oligonucleotides synthesized by GIBCO-BRL (Burlington, ON). Gene-specific PCR primers for Bax were purchased from Sigma (St. Louis, MO). The oligonuleotide primers were 5'-GTT TCA TCC AGG ATC GAG CAG-3' (sense), 5'-CAT CTT CTT CCA GAT GGT GA-3' (antisense). Product length was 487 base pairs. The specific rat GAPDH amplimers were from Clontech (5507-3) with an expected GAPDH size of 986 base pairs. PCR amplification was carried out in 30 cycles of denaturation at $94^{\circ} \mathrm{C}$ for 45 seconds, annealing at $53^{\circ} \mathrm{C}$ (Bax) and $60^{\circ} \mathrm{C}(\mathrm{GAPDH})$ for 45 seconds, elongation at $72^{\circ} \mathrm{C}$ for 120 seconds with an additional 7 -minute final extension at $72^{\circ} \mathrm{C}$ using an
Eppendorf MasterCycler (Eppendorf, Westbury, NY). The PCR product was analyzed using a $1.2 \%$ agarose gel. Identity of PCR products was confirmed by sequencing at the DNA-sequencing facility of the Manitoba Institute of Cell Biology.

\section{Statistical analysis}

Data are presented as mean \pm SEM. The $n$ value refers to the number of replicates performed for each study. Data were analyzed using oneway ANOVA with Student-Newman-Keuls post hoc test taking $p<0.05$ as the level for significance.

\section{Results}

\section{Intracellular free radical levels}

Cellular free radical levels were assessed using the dichlorofluorescein (DCF) assay. Figure 1 shows DCF fluorescence values from $\mathrm{H}_{2} \mathrm{O}_{2}$ induced oxidative stress treated with diltiazem $(2.5$ and $10 \mu \mathrm{M})$, silymarin $(1000 \mu \mathrm{g} / \mathrm{L})$ or the combination diltiazem $(2.5 \mu \mathrm{M}$ or $10 \mu \mathrm{M})$ and silymarin $(1000 \mu \mathrm{g} / \mathrm{L})$ for PLC cells (Figure 1 left) or diltiazem $(2.5$ and $10 \mu \mathrm{M})$, silymarin $(10$ and $1000 \mu \mathrm{g} / \mathrm{L})$, or diltiazem $(2.5$ or $10 \mu \mathrm{M})$ and silymarin $(10$ or $1000 \mu \mathrm{g} / \mathrm{L})$ for Chang cells (Figure 1 right). Trolox $(1 \mathrm{mM})$ and Vitamin $\mathrm{E}(100 \mu \mathrm{M})$ were used as positive controls. Diltiazem, silymarin and the combination of diltiazem and silymarin all statistically reduced the free radical levels in PLC ( $n=6)$ and Chang cells $(n=6 ; p<0.01)$, as did Trolox and Vitamin $\mathrm{E}$ in the PLC cells $(\mathrm{p}<0.01)$ over that of controls (no drug treatment). DCF fluorescence was not statistically different between diltiazem and silymarin treatments. The combination of diltiazem and silymarin, however, further reduced the DCF fluorescence from that of either silymarin or diltiazem alone as shown in Figure $1(\mathrm{p}<0.01)$, suggesting a possible difference in their modes of action in inactivating free radicals.

\section{Cell viability/proliferation}

Cellular viability/proliferation was assessed using the MTT assay (Figure 2). Diltiazem produced a statistically significant increase in cell number from control (no drug treatment) values ( $7.5 \%$ and $10.8 \%$ for $2.5 \mu \mathrm{M}$ and $10 \mu \mathrm{M}$ diltiazem for Chang cells, respectively, $\mathrm{n}=7$; and $5.8 \%$ and $11.5 \%$ for $2.5 \mu \mathrm{M}$ and $10 \mu \mathrm{M}$ diltiazem for PLC cells, respectively, $\mathrm{n}=7$ ). Silymarin treatment resulted in an $11.5 \%$ and $11.7 \%$ increase in in cell viability/proliferation for PLC and Chang cells, respectively. The addition of silymarin $(1000 \mu \mathrm{g} / \mathrm{L})$ to $2.5 \mu \mathrm{M}$ diltiazem further statistically enhanced cell proliferation over that of diltiazem alone ( $13.5 \%$ for PLC and $20.6 \%$ for Chang), while increasing the diltiazem concentration to $10 \mu \mathrm{M}$ also resulted in a statistical increase in PLC (19.2\%) and Chang (28.2\%) cell proliferation.

\section{Cellular ATP levels}

To further understand the protective nature of diltiazem, silymarin, and the combination of diltiazem and silymarin we investigated cellular ATP levels following drug treatment. Drug treatment did not significantly affect cellular ATP levels when oxidative stress was absent. However, as shown in Figure 3 following $\mathrm{H}_{2} \mathrm{O}_{2}$ treatment, ATP levels were significantly $(\mathrm{p}<0.001)$ higher after all drug treatment than control (no drug treatment) in both Chang $(n=6)$ and PLC $(n=5)$ cells. Silymarin $(1000 \mu \mathrm{g} / \mathrm{L})$ by itself also significantly increased the ATP levels over that of diltiazem in both cell lines $(p<0.05)$. The addition of silymarin to diltiazem further enhanced the ATP levels than diltiazem alone in both cell lines $(p<0.001)$. There was no statistical enhancement of ATP levels when the diltiazem dose was increased from $2.5 \mu \mathrm{M}$ to $10 \mu \mathrm{M}$ in the presence of silymarin $(1000 \mu \mathrm{g} / \mathrm{L})$ in either the PLC or chang cells. 


\section{Bax protein level}

To further understand the protective nature of diltiazem and silymarin we investigated whether drug treatment affected the proapoptotic protein Bax. Figure 4 shows a representative Western blot following drug treatment in Chang cells while Figure 5 summarizes the data from all studies. Diltiazem $(2.5 \mu \mathrm{M}$ and $10 \mu \mathrm{M})$ significantly reduced the levels of Bax from control cells in both Chang $(n=5)$ and
PLC $(\mathrm{n}=5)(\mathrm{p}<0.001)$. Increasing the diltiazem concentration to $10 \mu \mathrm{M}$ was associated with a further improvement in Bax level suggesting a reduction in apoptotic activity in both cell lines. The reduction in Bax level was greater in the presence of silymarin than control $(\mathrm{p}<0.001)$ and significantly greater than diltiazem administration in both Chang and PLC cell lines. The combination of diltiazem and silymarin further statistically reduced Bax levels than either diltiazem or silymarin alone in both cells lines (Figure 4).

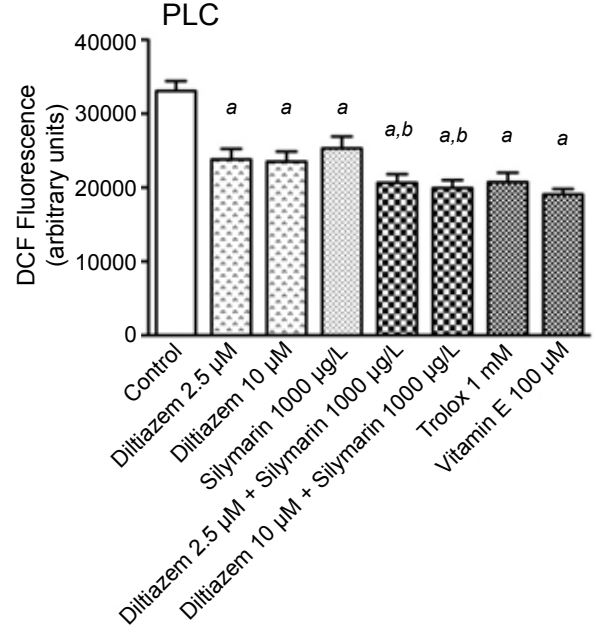

Drug Treatment

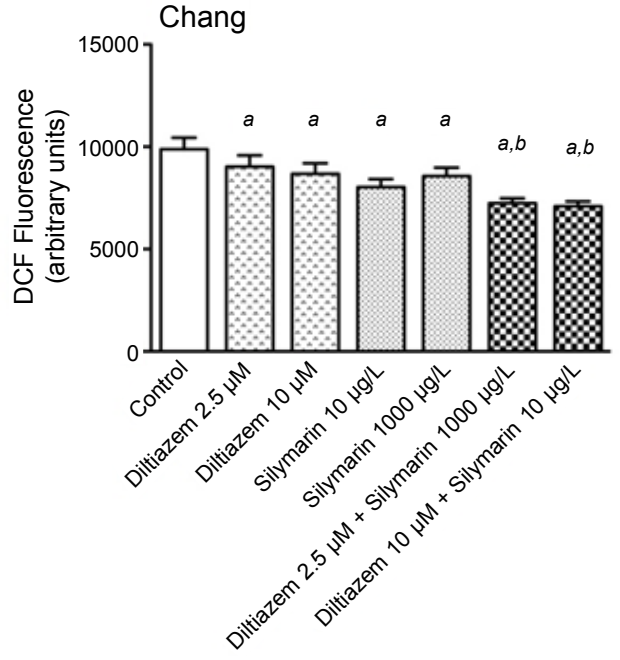

Drug Treatment

Figure 1: DCF fluorescence of PLC (left, $n=6$ ) and Chang (right, $n=6$ ) cells following oxidative stress induced by hydrogen peroxide. Cells were cultured in 96-well

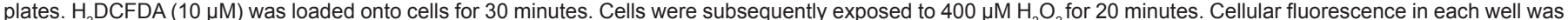
measured and immediately recorded. Incubation with diltiazem and/or silymarin statistically reduced the free radical levels from control values, as did Trolox and Vitamin E. Data are represented as mean $\pm \mathrm{SEM}$; ${ }^{\mathrm{a}} \mathrm{p}<0.01$ from control, ${ }^{\mathrm{a}, \mathrm{b}} \mathrm{p}<0.001$ from control and single drug treatment; one tail distribution.

PLC

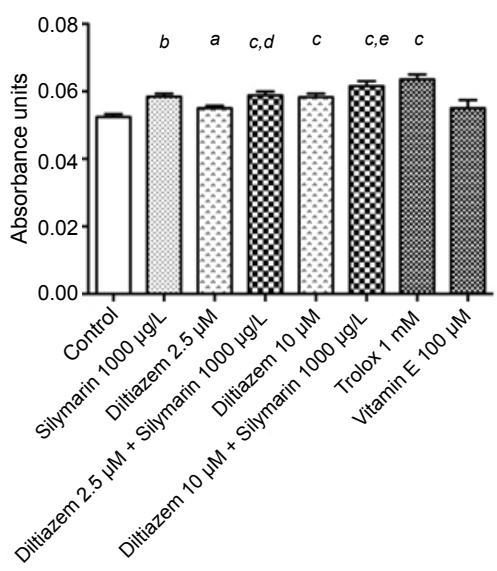

Drug Treatment
CHANG

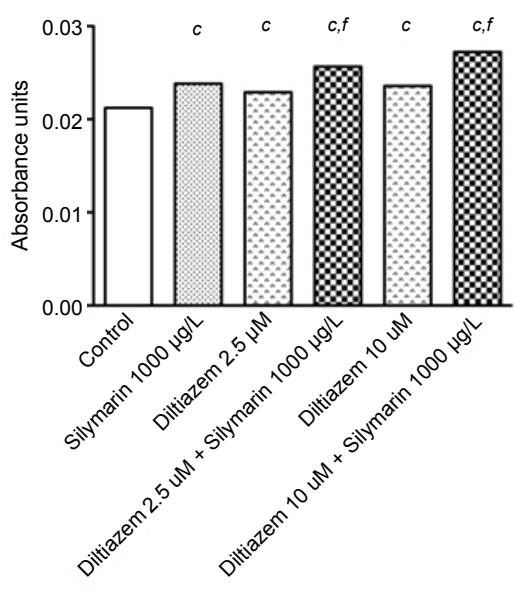

Drug Treatment

Figure 2: Cell viability/proliferation as assessed by the MTT assay in PLC (left) and Chang (right) cells. Data represent mean $\pm \mathrm{SEM} ; \mathrm{n}=7 ;{ }^{a} \mathrm{p}<0.05$ from control, ${ }^{b} \mathrm{p}<0.01$ from control; ${ }^{c} \mathrm{p}<0.001$ over control; ${ }^{d} \mathrm{p}<0.01$ over $2.5 \mu \mathrm{M}$ diltiazem alone, PLC cells; ${ }^{e} \mathrm{p}<0.05$ over $10 \mu \mathrm{M}$ diltiazem alone, PLC cells; ${ }^{f} \mathrm{p}<0.001$ from $2.5 \mu \mathrm{M}$ or $10 \mu \mathrm{M}$ diltiazem alone, Chang cells; one tail distribution. 

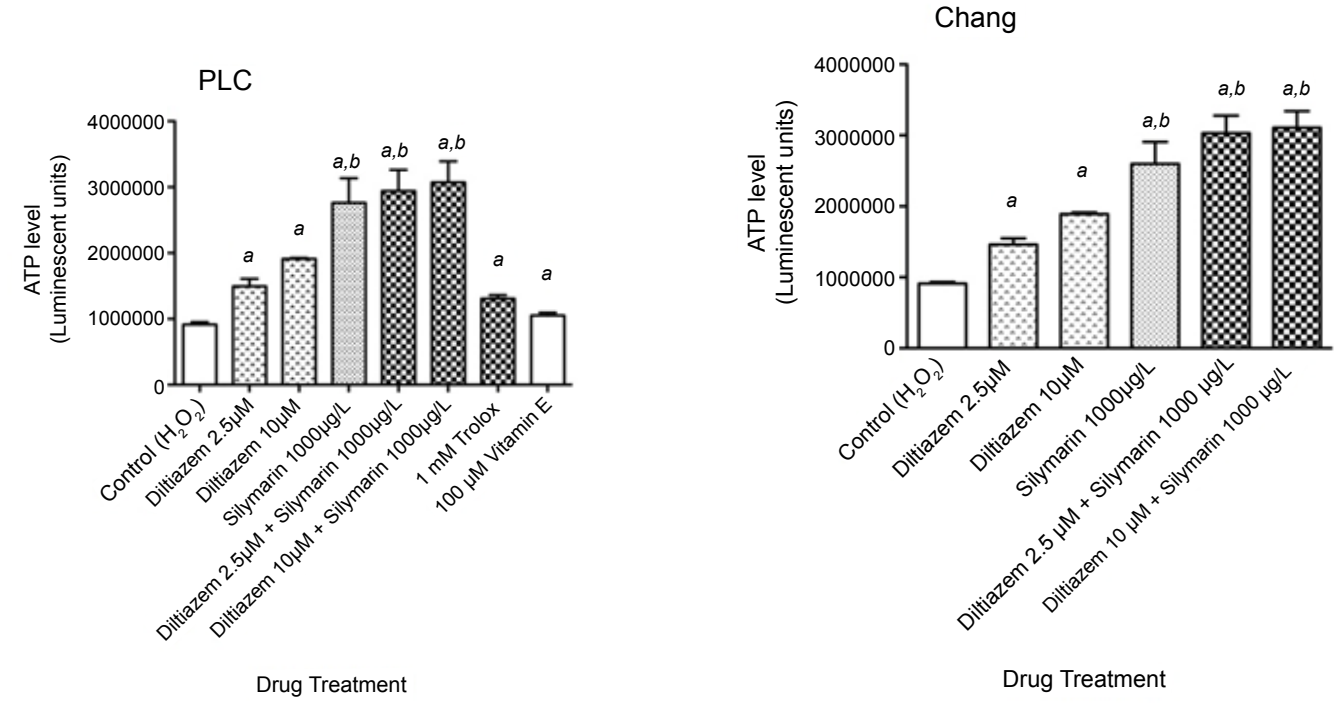

Figure 3: Cellular ATP levels in PLC (left, $n=5$ ) and Chang (right, $n=6$ ) cells as assessed by the bioluminescent assay. Data represent mean \pm SEM; ${ }^{2} p<0.001$ from control; ${ }^{b} \mathrm{p}<0.05$ from diltiazem alone; one tail distribution.

\section{Bax Western blot}

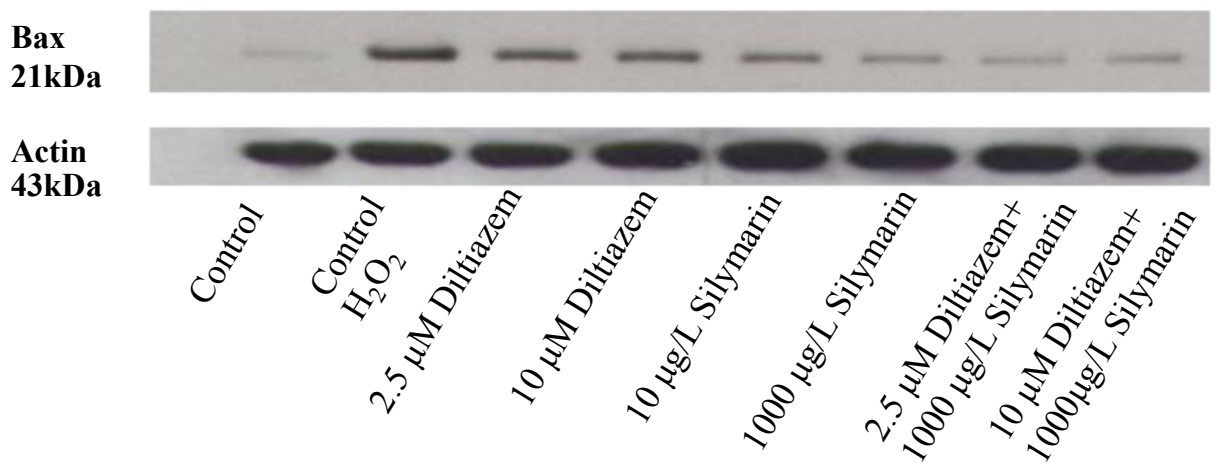

Figure 4: Expression of Bax in control and drug treated Chang cells. Bax activity was used as the marker of apoptosis. Blank contained serum-free media cells while control contained serum-containing media following $\mathrm{H}_{2} \mathrm{O}_{2}$ treatment. Apoptosis was induced by $\mathrm{H}_{2} \mathrm{O}_{2}$ treatment.

\section{Bax mRNA level}

To further elucidate the protective nature of drug treatment we investigated the effects of diltiazem and silymarin on Bax mRNA to understand if the protective function is related to enhanced degradation of the pro-apoptotic markers or transcription. Figure 6 shows a representative scan of RT-PCR Bax mRNA while Figure 7 summarizes data from the Chang cell line $(n=3)$. All drug treatments statistically reduced the Bax mRNA levels from control levels $(\mathrm{p}<0.001)$. Silymarin at $1000 \mu \mathrm{g} / \mathrm{L}$ was more effective than diltiazem in reducing Bax mRNA levels ( $\mathrm{p}<0.001)$. The addition of silymarin to diltiazem further reduced the Bax mRNA level than use of either drug alone $(\mathrm{p}<0.01)$. However, there was no statistical difference between the combination of $2.5 \mu \mathrm{M}$ diltiazem and $1000 \mu \mathrm{g} / \mathrm{L}$ silymarin and $10 \mu \mathrm{M}$ diltiazem and $1000 \mu \mathrm{g} / \mathrm{L}$ silymarin $(\mathrm{p}>0.05)$.

\section{Discussion}

The objective of the present study was in determining the hepatoprotective effect of diltiazem at low doses in cell cultures and whether the addition of silymarin has a significant improvement in this effect. Diltiazem has been shown to be an effective antioxidant at clinically relevant doses. Mason et al. [15] suggested that the antioxidant potency of calcium channel blockers is related to the compounds' relative affinity for the lipid bilayer and ability to modulate membrane thermodynamic properties. These properties were thought to be independent of calcium channel inhibition and suggested that diltiazem is most effective in lipophilic domains. Using isolated microsomes Rajaraman et al. [8] reported that diltiazem (concentration range 5-1000 $\mu \mathrm{M}$ ) suppressed free radical levels following exposure of microsomes to hydrogen peroxide. They further showed that the 

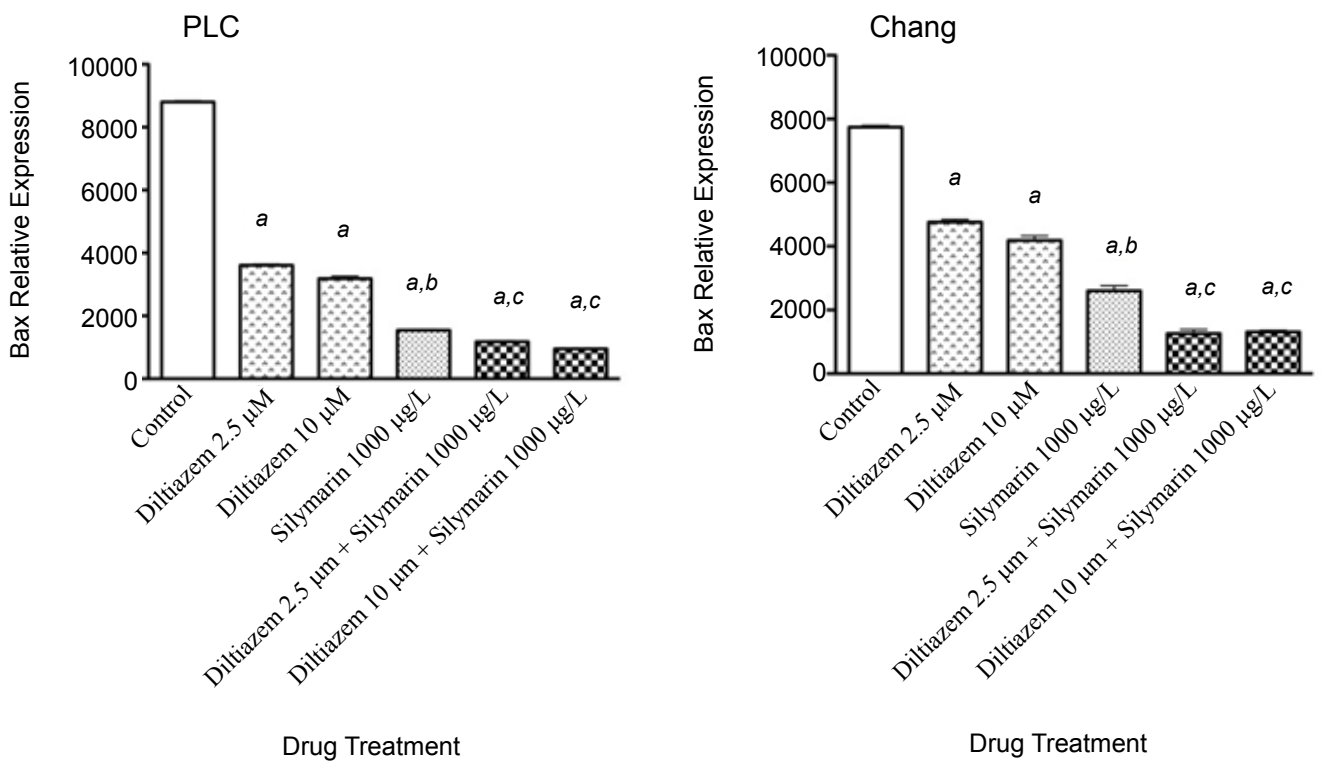

Figure 5: The relative Bax expression in Chang and PLC cells calculated by normalizing Bax optical density against actin. Data represent mean \pm SEM; $n=5$ for both Chang and PLC cells; ${ }^{a} p<0.001$ from control, ${ }^{b} p<0.001$ over that of diltiazem alone, ${ }^{c} p<0.01$ over that of silymarin alone; one tail distribution.

antioxidant property was present only with $d$-cis diltiazem while $l$-cis diltiazem was without effect, suggesting stereospecificity in its action. Moreover, the study authors noted that the antioxidant effect was not immediate but was associated with a significant lag time, suggesting that the seterospecificity of diltiazem is important for inserting itself into a bilayer component of the cell. In the present study we extended our work investigating whether diltiazem possesses hepatoprotective properties at subclinical doses using hepatocyte cultures. Since it is thought that diltiazem inserts itself into lipid membranes, we further investigated whether the addition of silymarin provided an additive hepatoprotective effect, reasoning that diltiazem protects lipid membranes while silymarin would act in the hydrophilic domain of the cell.

Silymarin has been used for many years in the treatment of liver diseases [16], has been reported to be of value as an adjuvant to the treatment of alcoholic induced liver disease $[11,17]$ and in the treatment of $\mathrm{CCl}_{4}$-induced oxidative damage [10]. The mechanism for this effect is thought to be its ability to trap free radicals, thereby, producing a membrane stabilizing effect [18]. Treatment with low dose silymarin is not thought to provide any beneficial effect while higher doses have been shown to provide a therapeutic effect in reversing the fibrosis produced from prolonged $\mathrm{CCl}_{4}$-treatment in animals [18]. Moreover, Boigk et al. showed that silymarin retards collagen accumulation in early and advanced biliary fibrosis [13]. Because of its hepatoprotective properties silymarin, as a plant extract, is used as a standard in models of liver disease to which other plant extracts are measured [19].

Silymarin is known to reduce the rise in intracellular $\mathrm{Ca}^{2+}$ levels induced by ter-butyl hydroperoxide in rat hepatocytes, suggesting that the hepatoprotective effect of silymarin is not only due to the inhibition of lipid peroxidation but also modulation of intracellular calcium levels [20]. The reduction of free radical damage to phospholipids within the cell membrane would further limit any increase in nonspecific calcium permeability induced by membrane oxidation. Silymarin may also have an indirect effect on cells. Since the ATP levels of cells in the presence of silymarin were much greater than those exposed to diltiazem alone, silymarin may mediate preservation of mitochondrial function such that the cell is able to continually excrete calcium ions during phases of intracellular calcium overload. The ability to maintain calcium flux may be due to either silymarin's effect as an antioxidant by reducing intracellular free radical levels and/or some direct effect on mitochondria through modulation of mitochondrial calcium ion channels.

Silibinin, the active constituent of silymarin, is known to protect cardiac myocyte injury through the mitochondrial pathway [21] Silibinin has been shown to inhibit the release of the pro-apoptotic cytochrome $\mathrm{c}$ from mitochondria and increase the expression of the anti-apoptotic Bcl-2 family protein. Thus, silibinin inhibits Bax translocation from the cytoplasm to the mitochondria. Similar results have been reported in UV-induced cell apoptosis in human malignant melanomas [22]. Whether this effect is primarily a direct result of its antioxidant action or secondarily to the inhibition of the release of the pro-apoptotic factors is not clear. In our study diltiazem, at subclinical doses, reduced Bax levels following oxidative stress. The addition of silymarin further reduced these levels, which were likely a result from reduced Bax mRNA as shown by RT-PCR. Thus, diltiazem's and silymarin's effects are likely upstream from the translocation of Bax from the cytoplasm to the mitochondria and may occur at the gene level.

Both diltiazem and silymarin reduced the ROS levels in Chang and PLC cells. This effect is not surprising given our previous work with diltiazem showing that diltiazem reduces ROS levels in microsomal studies [8] and the many reports suggesting silymarin's hepatoprotective effect is through its antioxidant activity $[10,12]$. Of significance was the finding of an additive effect in the reduction of ROS levels when silymarin was added to diltiazem. The additive effect suggests that silymarin's antioxidant property may be limited to the cytosol while diltiazem's effect extends to the cell membrane or other intracellular membranes. Moreover, silymarin, at $10 \mu \mathrm{g} / \mathrm{L}$ and $1000 \mu \mathrm{g} / \mathrm{L}$, resulted in the same effect showing that there was no benefit in administering higher doses.

Both silymarin and diltiazem were as effective in enhancing cell 
viability/proliferation. The addition of silymarin to diltiazem resulted in a higher viability/proliferation rate than use of any one compound alone. The enhanced rate is in contrast to that reported by Bhatia et al. [23]. That group reported that silymarin at doses of $100 \mu \mathrm{M}$ inhibited cell growth of prostate, breast and cervical human carcinoma cells grown in culture but had little effect on cell viability. In the present study the addition of silymarin to diltiazem slightly enhanced cell growth, although the increase was statistically significant. The combination treatment resulted in about an $11 \%$ enhancement in the number of cells at the lowest tested dose compared to diltiazem alone. Whether it is an actually increase in proliferation or enhanced cell viability, however, is not clear. Since both silymarin and diltiazem increased ATP levels in cells subjected to oxidative stress, enhanced viability is likely. Similar results were reported by Ligeret et al. [24]. Using a cold preservationwarm reperfusion isolated liver model, they reported that silibinin increased ATP levels (39\%) and decreased oxidative stress to values observed in control nonischemic livers. Diltiazem may further enhance cell viability by inhibiting the mitochondrial calcium channel during calcium overload. A direct antioxidant effect on the mitochondrial membrane may also contribute to cell viability.

In conclusion, the present study shows that diltiazem at subclinical doses substantially reduced ROS levels, enhanced ATP levels as well as cell proliferation when hepatocytes were subjected to oxidative stress

\section{RT-PCR}

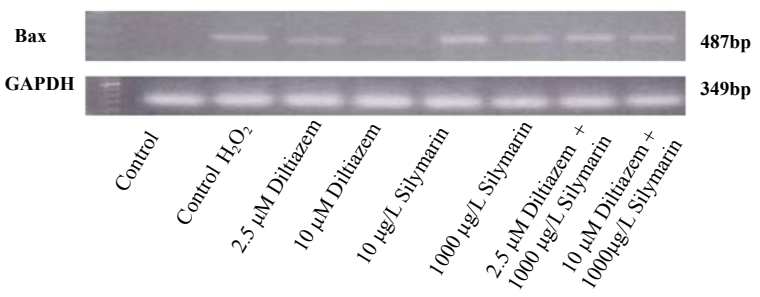

Figure 6: RT-PCR image of Bax and loading control GAPDH in control and drug treated Chang cells.

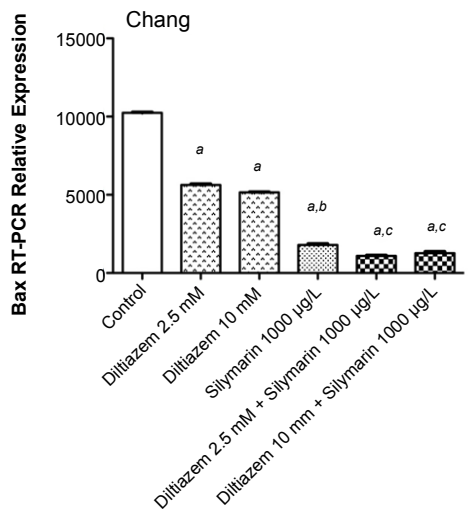

Drug Treatment

Figure 7: The RT-PCR results of Bax mRNA expression in Chang cells calculated by normalizing Bax mRNA optical density against GAPDH. Data represent mean \pm SEM; $n=3 ;{ }^{a} p<0.001$ over control, ${ }^{b} p<0.001$ over diltiazem alone, ${ }^{c} p<0.01$ over silymarin alone; one tail distribution. by the addition of hydrogen peroxide. The improved cell function was accompanied by reduced Bax mRNA levels and reduced Bax levels. Moreover, the addition of silymarin to diltiazem showed a further beneficial effect by reducing ROS levels, enhancing ATP levels, and reducing Bax mRNA and Bax levels.

\section{Acknowledgement}

This study was supported by a grant from the Canadian Institute of Health Research, the Manitoba Health Research Council, and Howard J Smith \& Associates Pty Ltd, Melbourne, Australia.

\section{References}

1. Bogaert MG (1996) How do calcium channel blockers prevent cardiovascular events. Are they all alike? Drugs 52: 3-7.

2. Little WC, Cheng CP (1994) Vascular versus myocardial effects of calcium antagonists. Drugs 47: 45-46.

3. Hisanaga M, Nakajima Y, Wada T, Kanehiro H, Fukuoka T, et al. (1993) Protective effect of the calcium channel blocker diltiazem on hepatic function following warm ischemia. J Surg Res 55: 404-410.

4. Romero G, Lasheras B, Sainz Suberviola L, Cenarruzabeitia E (1994) Protective effects of calcium channel blockers in carbon tetrachloride-induced liver toxicity. Life Sci 55: 981-990.

5. Satorres J, Perez-Mateo M, Mayol MJ, Esteban A, Graells ML (1995) Protective effect of diltiazem against acetaminophen hepatotoxicity in mice. Liver 15: 16 19.

6. Alov P, Koleva M, Kastelova A (1999) In vitro effects of calcium channe blockers and beta-adrenergic blocking agents on microsomal lipid perocidation and cytochrome p-450 content. Exp Toxicol Pathol 51: 277-281.

7. Farghali H, Kmonickova E, Lotkova H, Martinek J (2000) Evaluation of calcium channel blockers as potential hepatoprotective agents in oxidative stress injury of perfused hepatocytes. Physiol Res 49: 261-268.

8. Rajaraman G, Wang G, Smith HJ, Gong Y, Burczynski FJ (2007) Effect of diltiazem isomers and thiamine on piglet liver microsomal peroxidation using dichlorofluorescein. J Pharm Pharm Sci 10: 380-387.

9. Gharagozloo M, Amirghofran Z (2007) Effects of silymarin on the spontaneous proliferation and cell cycle of human peripheral blood leukemia T cells. J Cancer Res Clin Oncol 133: 525-532.

10. Naik SR, Panda VS (2007) Antioxidant and hepatoprotective effects of Ginkgo biloba phytosomes in carbon tetrachloride-induced liver injury in rodents. Liver Int 27: 393-399.

11. Das SK, Vasudevan DM (2006) Protective effects of silymarin, a milk thistle (Silybium marianum) derivative on ethanol-induced oxidative stress in liver. Indian J Biochem Biophys 43: 306-311.

12. Pradeep K, Mohan CV, Gobianand K, Karthikeyan S (2007) Silymarin modulates the oxidant-antioxidant imbalance during diethylnitrosamine induced oxidative stress in rats. Eur J Pharmacol 560: 110-116.

13. Boigk G, Stroedter L, Herbst H, Waldschmidt J, Riecken EO, et al. (1997) Silymarin retards collagen accumulation in early and advanced biliary fibrosis secondary to complete bile duct obliteration in rats. Hepatology 26: 643-649.

14. Muriel P, Moreno MG (2004) Effects of silymarin and vitamins E and C on liver damage induced by prolonged biliary obstruction in the rat. Basic Clin Pharmacol Toxicol 94: 99-104.

15. Mason RP, Mak IT, Trumbore MW, Mason PE (1999) Antioxidant properties of calcium antagonists related to membrane biophysical interactions. Am J Cardiol 84: 16L-22L.

16. Pradhan SC, Girish C (2007) Hepatoprotective herbal drug, silymarin from experimental pharmacology to clinical medicine. Indian J Med Res 124: 491504

17. Saller R, Meier R, Brignoli R (2001) The use of silymarin in the treatment of liver diseases. Drugs 61: 2035-2063.

18. Tsai JH, Liu JY, Wu TT, Ho PC, Huang CY, et al. (2008) Effects of silymarin on the resolution of liver fibrosis induced by carbon tetrachloride in rats. $\mathrm{J}$ Viral Hepat15: 508-514.

19. Fakurazi S, Hairuszah I, Nanthini U (2008) Moringa oleifera Lam prevents 
Citation: Burczynski FJ, Yan J, Gong Y, Nguyen D, Wang G, et al. (2013) The Hepatoprotective Effect of Diltiazem and Silymarin. Nat Prod Chem Res 1: 111. doi:10.4172/ 2329-6836.1000111

acetaminophen induced liver injury through restoration of glutathione level. Food Chem Toxicol 46: 2611-2615.

20. Farghali H, Kamenikova L, Hynie S, Kmonickova E (2000) Silymarin effects on intracellular calcuim and cytotoxicity: a study in perfused rat hepatocytes after oxidative stress injury. Pharmacol Res 41: 231-237.

21. Zhou B, Wu LJ, Li LH, Tashiro S, Onodera S, et al. (2006) Silibinin protects against isoproterenol-induced rat cardiac myocyte injury through mitochondrial pathway after up-regulation of SIRT1. J Pharmacol Sci 102: 387-395.
22. Li LH, Wu LJ, Tashiro SI, Onodera S, Uchiumi F, et al. (2006) The roles of Akt and MAPK family members in silymarin's protection against UV-induced A375-S2 cell apoptosis. Int Immunopharmacol 6: 190-197.

23. Bhatia N, Zhao J, Wolf DM, Agarwal R (1999) Inhibition of human carcinoma cell growth and DNA synthesis by silibinin, an active constituent of milk thistle: comparison with silymarin. Cancer Lett 147: 77-84.

24. Ligeret H, Brault A, Vallerand D, Haddad Y, Haddad PS (2008) Antioxidant and mitochondrial protective effects of silibinin in cold preservation-warm reperfusion liver injury. J Ethnopharmacol 115: 507-514. 